\title{
Sutureless Aortic Valve Replacement: A Theoretical Analysis of The Effective Orifice Area in Comparison With Stented Valves
}

\author{
IIgor Belluschi ${ }^{1}$, Stefano Moriggia ${ }^{1}$, Simona Nascimbene $^{1}$, Nicola Buzzatti ${ }^{1}$, Ottavio Alfieri $^{1}$
}

1) Department of Cardiac Surgery, San Raffaele University Hospital, Milan, Italy

\begin{abstract}
Objective: Sutureless aortic valve replacement has recently been introduced as an alternative to conventional surgery to minimize the operative risk in elderly patients, shortening the cardiopulmonary bypass time and enhancing the minimally invasive approach. The aim of our study is to demonstrate that the sutureless bioprosthesis, compared to a conventional sutured prosthesis, has a corresponding larger effective orifice area, resulting in a better hemodynamic performance of the left ventricle.

Materials and methods: In this prospective observational study, between January 2014 and September 2015, among our population of 37 sutureless aortic valve replacements, we examined 17 patients (sutureless, A group), in which a second measurement with a standard stented valve sizer has been performed during surgery. As a control group, we analyzed 10 additional aortic valve replacements who received conventional stented bioprosthesis (sutured, B group), in which an additional measurement with the sutureless sizer has been used to compare size and effective orifice areas differences between the sutureless and the sutured valves for any given annulus.

Results: The size of the implanted bioprosthesis was $23,1 \pm 1,9 \mathrm{~mm}$ and $23 \pm 1,6 \mathrm{~mm}$ for the sutureless and sutured groups, respectively. In both groups, there were significative differences between the effective orifice areas of the implanted and the control sized prosthesis, always in favour of the sutureless valve (sutureless, A group: $2,6 \pm 0,3$ vs 1,4 $\pm 0,0 \mathrm{~cm} 2, \mathrm{p}<0,001$; sutured, B group: $1,5 \pm 0,2$ vs $2,9 \pm 0,3 \mathrm{~cm} 2, \mathrm{p}<0,001)$.

Conclusions: Previous studies compared nominal sizes regardless of the effective orifice areas. For the first time, we analyzed the areas of the sutureless versus sutured bioprosthesis. For every single patient considered, the effective orifice area was significantly larger with the sutureless rather than with the sutured bioprosthesis that could fit. In sutureless aortic valve replacements, the benefits go far beyond the cardiopulmonary bypass and cross-clamp time reduction, providing larger areas and less risk of patient-prosthesis mismatch.
\end{abstract}

Keywords: Sutureless, aortic valve, Perceval, Effective Orifice Area 


\section{Introduction}

Sutureless aortic valve replacement (SU-AVR) with the innovative Perceval bioprosthesis (Sorin Group S.p.A., Saluggia, Italy) has recently been introduced as an alternative to conventional surgery to minimize the operative risk in elderly patients. Advantages consist of both shortening the cardiopulmonary bypass (CPB) time and enhancing the minimally invasive approach. ${ }^{(1,2)}$ From 2007, this device underwent successfully to three europeans trials (the Perceval Pilot trial, the Perceval Pivotal trial and the CAVALIER trial) obtaining the CE mark in 2011. Nowadays, it has been implanted in more than 15.000 patients.

Several studies confirm how the Perceval valve has been widely used even in off-label indications such as in concomitant mitral valve replacement ${ }^{(3)}$, endocarditis $^{(4)}$, bicuspid aortic valve ${ }^{(5)}$ and aortic regurgitation. ${ }^{(6)}$ However, the advantages of the sutureless device go far beyond the reduction of the CPB time. It is a wellknown fact that valvular prosthesis with larger Effective Orifice Areas (EOAs) have a better impact on the hemodynamics of the left ventricle (LV) as shown by Gonzalez et al.(7)

The aim of our study is to demonstrate that the sutureless bioprosthesis, compared to a conventional sutured prosthesis, has a corresponding larger EOA, resulting in a better hemodynamic performance of the LV.

\section{Materials and Methods}

\section{Study description and patient population}

In this prospective observational study, between January 2014 and September 2015, among our population of 37 SU-AVRs at San Raffaele University Hospital (Milan, Italy), we examined 17 patients (A group), in which a second measurement with a standard stented valve sizer (Medtronic Hancock II) has been performed during surgery. As a control group, we analyzed 10 additional aortic valve replacements (AVRs) (B group) who received a conventional stented bioprosthesis, in which an additional measurement with the Perceval sutureless sizer has been used to compare size and EOA differences between the sutureless and the sutured valves for any given annulus. The prosthesis implanted in the B group included Carpentier-Edwards Perimount $(\mathrm{n}=2)$, St. Jude Trifecta $(\mathrm{n}=2)$ and Medtronic Hancock II $(n=6)$. This case/control-like approach should reduce the statistical bias.

\section{Perceval sutureless valve}

The innovative sutureless Perceval bioprosthesis (Sorin Group S.p.A., Saluggia, Italy; Figure 1) consists of a double sheet bovine pericardium fixed on a nitinol stent (alloy of nickel and titanium) which supports strong deformation and can return to its original shape when the stressor is removed. The stent is made of two rings (outflow ring and inflow ring), connected by 9 struts: 6 sinusoidal and 3 straight commissural ones. It is necessary to support the valve and hold it in place whitin the aortic root. A thin layer of Carbofilm ${ }^{\mathrm{TM}} \mathrm{im}$ proves biocompatibility. The super-elastic alloy allows the adaption of the device to the anatomy of the aorta. As reported by Della Barbera et al. ${ }^{(8)}$, the valve's atraumatic collapsing system does not affect the integrity of the device's leaflets.

\section{Sutureless surgical technique}

In the SU-AVRs population, a partial upper sternotomy (J-sternotomy) in the third intercostal space or in the fourth intercostal space or a full median sternotomy was performed to obtain access to the aorta, according to the surgeon's preference. After systemic hepariniza-

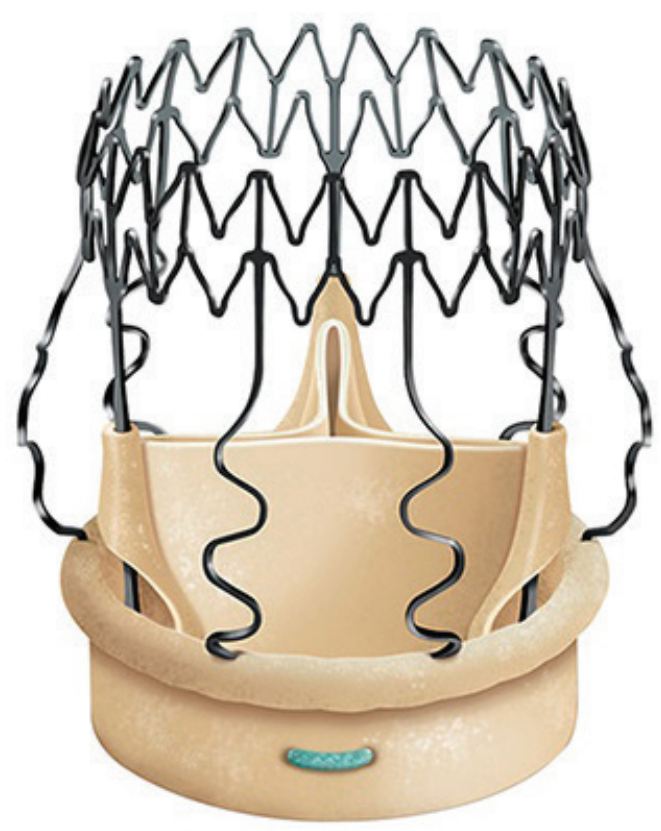

Figure 1. The innovative sutureless Perceval bioprosthesis (Sorin Group S.p.A., Saluggia, Italy). 
tion, a standard CPB was performed, cannulating the aorta, the right atrium and using a vent into the right superior pulmonary vein. After cross-clamping and the cardioplegia delivery, a transverse aortotomy was performed $1 \mathrm{~cm}$ distal to the sinotubular junction to avoid the device interference during the closure of the aortotomy. The native valve was removed and the annulus decalcified. The sizing of the annulus was performed using the designed Perceval sizer. The Perceval valve is available in 4 sizes: size $\mathrm{S}$, to be implanted in annuli from 19 to $21 \mathrm{~mm}$; size $\mathrm{M}$, to be implanted in annuli from 21 to $23 \mathrm{~mm}$; size L, for patients with annuli of 23 to $25 \mathrm{~mm}$; and size $\mathrm{XL}$, for diameters varing from 25 to $27 \mathrm{~mm}$. Three 3-0 Prolene guiding sutures were positioned $2 \mathrm{~mm}$ below the nadir of the each native leaflet insertion line and then passed through the prosthesis' button hole to obtain a perfect alignment of the device. The valve was loaded onto an holder through a collapsing system and then deployed into the aortic root. A post-dilation with a balloon catheter at 4 Atm for 30 seconds and the instillation of warm saline solution guarantee the perfect positioning of the device. Then the guiding sutures are removed and the aorta is closed in the usual fashion (Prolene 5-0). The cross-clamp and the CPB are finally dismissed. Perceval and sutured implants were performed by two trained surgeon. In the B group, patients underwent a conventional AVR. The decision whether to implant the sutureless prosthesis or

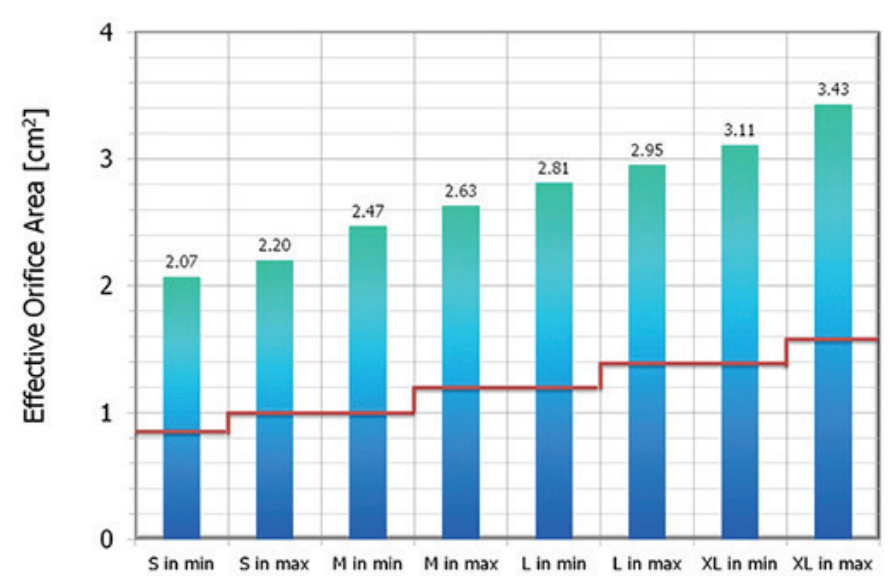

Figure 2. The image shows the Effective Orifice Areas of the Perceval bioprosthesis provided by Sorin Group S.p.A. For each prosthesis' nominal size (S-M-L-XL), the EOAs are expressed as a range (min-max) considering that each size covers a range of 2 annular diameters. The red line refers to the ISO 5840 minimal requirement. (Courtesy of Sorin Group S.p.A.). the conventional one was left to the surgeon's current practice. All the patients, even in B group, were suitable for the Perceval device, accordingly to the anatomical criteria of implantation.

\section{Prosthesis comparison}

Previous studies compared the sizes of the prosthesis to determine which valve is a better option for the patient and to prevent a patient-prosthesis mismatch. However, in most cases, the measures of the sizes provided by the manufacturers refer to the internal or the external diameter of the stent, regardless of the functional valve area.

Therefore, to give a precise theoretical analysis of the valve areas, we used the echographic projected EOA provided by the manufacturers (in vivo EOA for sutured bioprosthesis and in vitro EOA for Perceval valve). For the Perceval bioprosthesis, each size covers a range of 2 annular diameters, therefore the EOA reported by Sorin (Sorin Group S.p.A.) varies from 2,07 to 2,20 $\mathrm{cm} 2$ for the $\mathrm{S}$ size; from 2,47 to $2,63 \mathrm{~cm} 2$ for the $\mathrm{M}$ size; from 2,81 to $2,95 \mathrm{~cm} 2$ for L size and from 3,11 to 3,43 for the XL size (Figure 2). The EOAs of the Hancock II valve provided by Medtronic (Medtronic, Minneapolis, MN, USA) were: $1,40 \pm 0,50 \mathrm{~cm} 2$ for size $21 ; 1,30 \pm 0,20$ $\mathrm{cm} 2$ for size 23; and 1,40 $\pm 0,30 \mathrm{~cm} 2$ for size 25 . The EOAs of the Trifecta prosthesis defined by St. Jude (St. Jude Medical, Minneapolis, MN, USA) were 1,58 cm2 and $1,94 \mathrm{~cm} 2$ for size 19 and 23 respectively. The EOA of the Perimount valve size 23 provided by CarpentierEdwards (Edwards Lifescience, Inc., Irvine, CA, USA) was $1,87 \pm 0,28 \mathrm{~cm} 2$.

\section{Statistical analysis}

The statistical analysis was performed on the EOAs given by the manufacturers. In the sutureless bioprosthesis, the EOA is provided as a range, therefore, for a more convincing analysis, we used the smallest and less favourable EOA value for each size. However, the numerical diameter value of the Perceval prosthesis is reported as mean of the range (i.e. for $\mathrm{S}$ size, range 19$21 \mathrm{~mm}$, we used $20 \mathrm{~mm}$ ).

For the data analisys the IBM SPSS Statistic Version 22 software was used (Armonk, NY, USA). Continuous variables are reported as mean $\pm \mathrm{SD}$ or median and 
interquartile range [IQR], while categorical variables are expressed as absolute value and by frequency (\%). For continuous variables, the normality of distribution was assessed with the Kolmogorov-Smirnov test. Differences between groups are calculated using Student's T test or Mann-Whitney's U test for normal and skewed variables respectively. Categorical variables were analyzed using the Fisher and $\chi^{2}$ tests. A p-value $<0,05$ was considered to indicate statistical significance.

\section{Results}

\section{Patients' Characteristics}

Patients' demographic is summarized in Table 1. Male patients were $41 \%$ and $80 \%$ in group $\mathrm{A}$ and $\mathrm{B}$, respectively $(\mathrm{p}=0,1)$. Patients' ages were similar between groups (A group: 79,3 $\pm 3,5$ y.o. vs B group: 74,2 $\pm 5,3$ y.o.; $\mathrm{p}=0,5)$. The mean $\pm \mathrm{SD}$ Logistic EuroSCORE and STS mortality score were $8,9 \pm 2,7 \%$ vs $6,0 \pm 2,3 \%$ $(\mathrm{p}=0,3)$ and $2,7 \pm 1,2$ vs $1,9 \pm 0,8 \%(\mathrm{p}=0,2)$ for the sutureless and sutured groups, respectively. No differencies were found analyzing obesity ( $30 \%$ vs $1 \% ; p=0,4)$, chronic obstructive pulmonary disease (COPD, $18 \%$ vs $20 \%, \mathrm{p}=0,9)$, diabetes ( $35 \%$ vs $20 \% ; \mathrm{p}=0,7)$, stroke rate $(6 \%$ vs $0 \% ; p=0,4)$ and polivascular disease $(18 \%$ vs $20 \% ; \mathrm{p}=0,9)$. In the sutureless group, 6 patients $(35 \%)$ were admitted with a III-IV NYHA functional class, while in the sutured one there was only 1 patient $(10 \%$; $\mathrm{p}=0,2)$. Preoperative transoesophageal echocardigrams reveal similar transvalvular mean $(41,1 \pm 13,0$ vs $51,4 \pm 11,8 \mathrm{mmHg} ; \mathrm{p}=0,5)$ and peak gradients $(66,3 \pm 22,0$ vs $79,4 \pm 16,2 \mathrm{mmHg}$; $\mathrm{p}=0,6$ ).

\section{Intraoperative Data}

A minimally invasive access (III-IV intercostal space J-sternotomy) was adopted in 8 patients $(47 \%)$ of the sutureless group ( $\mathrm{p}=0,012$; Table 1$)$. In all the patients who received a conventional sutured bioprosthesis, a full median sternotomy approach was performed. The cardiopulmonary bypass (CPB) time and cross-clamp time (XCT) were $61[54 ; 89]$ vs $70[61 ; 79]$ minutes $(\mathrm{p}=0,4)$ and $44[41 ; 68]$ vs $49[47 ; 68]$ minutes $(\mathrm{p}=0,2)$ in group A and B, respectively.

\section{Postoperative Results}

Postoperative transthoracic echocardiograms show a reduction of the transvalvular mean gradients (sutureless: $11,9 \pm 2,0$ vs sutured: $13,8 \pm 7,2 \mathrm{mmHg} ; \mathrm{p}=0,7$ ) and peak gradients (sutureless: $21,7 \pm 4,2$ vs sutured: $22,2 \pm 10,3 \mathrm{mmHg} ; \mathrm{p}=0,7$ ) in both groups. After surgery, only 1 case of more-than-mild aortic regurgitation was reported in the A group ( $6 \%$ vs $0 \% ; p=0,4)$, while no paravalvular leak (PVL) occured (Table 1). A statistical difference between groups was found to be significative when analysing the need of transfusions $(p=0,023)$. No differencies were registered when the rates of pacemaker implantation (PM, sutureless: $6 \%$ vs sutured: $0 \%$; $\mathrm{p}=0,4)$, acute kidney injury (AKI, $0 \%$ ) and stroke $(0 \%)$ were analyzed. The durations of total postoperative hospital stay (sutureless: $6[6 ; 7]$ vs sutured: 4 [4;7]; $\mathrm{p}=0,4)$ and the intensive care unit (ICU) stay (sutureless: $1[1 ; 2]$ vs sutured: $1[1 ; 1] ; p=0,6)$ did not differ among groups. No in-hospital deaths were registered in both groups.

\section{Effective Orifice Area Analysis}

The mean \pm SD size of the implanted bioprosthesis was $23,1 \pm 1,9 \mathrm{~mm}$ and $23 \pm 1,6 \mathrm{~mm}$ for group A (Perceval implanted, conventional valve measured) and B (conventional valve implanted, Perceval measured) respectively. In both groups there were significative differences between the EOAs of the implanted and the control sized prosthesis, always in favour of the sutureless Perceval valve. In fact, in the A group $(n=17)$, the mean EOA of the Perceval implanted valve was 2,6 \pm $0,3 \mathrm{~cm} 2$, while the EOA of the measured conventional stented prosthesis which could fit the same annulus was only $1,4 \pm 0,0 \mathrm{~cm} 2$, with a significative statistical difference of $\mathrm{p}<0,001$. On the other side, in the B group ( $\mathrm{n}=$ 10 ), the mean EOA of the conventional stented prosthesis implanted was 1,5 $\pm 0,2 \mathrm{~cm} 2$, while the EOA of the measured Perceval prosthesis which could fit the same annulus was 2,9 $\pm 0,3 \mathrm{~cm} 2$. Even for group B, the statistical difference was significative $(p<0,001)$ (Figure 3).

\section{Discussion}

In this prospective observational study, we presented our population of 37 patients who underwent a SU-AVR at San Raffaele University Hospital, focusing on 17 patients (A group) who received a second sizing during surgery with a conventional valve sizer. In 
Table 1. Patients' characteristics, intraoperative data and postoperative results.

\begin{tabular}{|c|c|c|c|}
\hline Patients' demographics & $\begin{array}{l}\text { A group (Perceval) } \\
\qquad(n=17)\end{array}$ & $\begin{array}{l}\text { B group (Sutured) } \\
(n=10)\end{array}$ & p-value \\
\hline Age (y.o.) & $79,3 \pm 3,5$ & $74,2 \pm 5,3$ & 0,5 \\
\hline Male patients (\%) & $7(41)$ & $8(80)$ & 0,1 \\
\hline Obesity (\%) & $5(30)$ & $1(1)$ & 0,4 \\
\hline BSA (m2) & $1,79 \pm 0,11$ & $1,87 \pm 0,09$ & 0,9 \\
\hline COPD (\%) & $3(18)$ & $2(20)$ & 0,9 \\
\hline REDO (\%) & $0(0)$ & $0(0)$ & - \\
\hline Diabetes (\%) & $6(35)$ & $2(20)$ & 0,7 \\
\hline Preop Stroke (\%) & $1(6)$ & $0(0)$ & 0,4 \\
\hline Polivascular disease (\%) & $3(18)$ & $2(20)$ & 0,9 \\
\hline STS mortality score (\%) & $2,7 \pm 1,2$ & $1,9 \pm 0,8$ & 0,2 \\
\hline Logistic EuroSCORE (\%) & $8,9 \pm 2,7$ & $6,0 \pm 2,3$ & 0,3 \\
\hline NYHA III-IV (\%) & $6(35)$ & $1(10)$ & 0,2 \\
\hline Preop transaortic mean gradient $(\mathrm{mmHg})$ & $41,1 \pm 13,0$ & $51,4 \pm 11,8$ & 0,51 \\
\hline Preop transaortic peak gradient $(\mathrm{mmHg})$ & $66,3 \pm 22,0$ & $79,4 \pm 16,2$ & 0,62 \\
\hline Annulus (mm) & $22,5[20,0 ; 23,3]$ & $21,0[20,5 ; 24,3]$ & 0,6 \\
\hline Preop Aortic regurgitation $\geq 2+(\%)$ & $4(24)$ & $3(30)$ & 0,7 \\
\hline Ministernotomy (\%) & $8(47)$ & $0(0)$ & 0,012 \\
\hline CPB time (min) & $61[54 ; 89]$ & $70[61 ; 79]$ & 0,4 \\
\hline XCT (min) & $44[41 ; 68]$ & $49[47 ; 68]$ & 0,2 \\
\hline Postop transaortic mean gradient ( $\mathrm{mmHg}$ ) & $11,9 \pm 2,0$ & $13,8 \pm 7,2$ & 0,7 \\
\hline Postop transaortic peak gradient (mmHg) & $21,7 \pm 4,2$ & $22,2 \pm 10,3$ & 0,7 \\
\hline Postop Aortic regurgitation $\geq 2+(\%)$ & $1(6)$ & $0(0)$ & 0,4 \\
\hline PVL (\%) & $0(0)$ & $0(0)$ & - \\
\hline Acute Kidney Injury (\%) & $0(0)$ & $0(0)$ & - \\
\hline Postop Stroke (\%) & $0(0)$ & $0(0)$ & - \\
\hline Bleeding requiring surgical revision (\%) & $1(6)$ & $0(0)$ & 0,4 \\
\hline PM (\%) & $1(6)$ & $0(0)$ & 0,4 \\
\hline Blood Units transfusions & $0[0 ; 3]$ & $0[0 ; 0]$ & 0,023 \\
\hline ICU stay (days) & $1[1 ; 2]$ & $1[1 ; 1]$ & 0,6 \\
\hline Postoperative hospital stay (days) & $6[6 ; 7]$ & $4[4 ; 7]$ & 0,4 \\
\hline In-hospital death (\%) & $0(0)$ & $0(0)$ & - \\
\hline \multicolumn{4}{|c|}{$\begin{array}{l}\text { BSA = Body Surface Area; COPD = Chronic Obstructive Pulmonary Disease; NYHA = New York Heart Association func- } \\
\text { tional class; CPB = Cardiopulmonary Bypass; XCT = Cross-Clamp Time; PVL = Paravalvular Leaks; } \\
\text { PM = Pacemaker; ICU = Intensive Care Unit }\end{array}$} \\
\hline
\end{tabular}


addition, during 10 conventional sutured AVRs which took place in the same period (B group), another sizing with the Perceval dedicated sizer was performed. The idea of a sutureless valve prosthesis was first described by Magovern and Cromie in 1962. ${ }^{(9)}$ The Perceval bioprosthesis does not need to be sutured, therefore it can be rapidly deployed, with the consequent reduction of cross-clamp time and $\mathrm{CPB}$, minimizing the patients' risk. $^{(10,11)}$ However, the advantages of the innovative sutureless bioprosthesis seem to go far beyond. The groups of Santarpino et al. and König et al. were the first to analyze the differences between sizes of the Perceval sutureless and the conventional stented valves. ${ }^{(1,12)}$ However, in most cases, the measures provided by the manufacturers refer to the internal or the external diameter of the stent, without specifing the functional valve area. There is no corrispondence among the sizes of different sutured valves. In fact the numerical prosthetic diameter is not standardized. ${ }^{(13)}$ Any previous analysis focusing on the prosthesis nominal size appear to be reductive for our purpose. Therefore, to have a more precise theoretical comparison of the valve areas and their performance, we used the echocardiographic EOA provided by the prosthesis' producers in a case/control fashion study to reduce the bias. To the authors' knowledge, considering the design of the study, this is the first theoretical analysis which compares the EOAs of the sutureless and the conventional prosthesis. Furthermore, in the transcatheter implantation era, the choice of a sutureless device with a larger EOA ensures a great Valve-in-Valve feasability. ${ }^{(14)}$

A limitation to our analysis consists of the use of projected EOAs values provided by the manufacturers. As a matter of fact, in the immediate intraoperative/ postoperative period, considering the hemodynamic variability due to the surgical catecholamine stress and volume load, the use of the continuity equation as a reliable method to estimate the EOA is still debated. However, during the follow-up, the 3-6 months transthoracic ecocardiography of the first patients in group A showed that the measured EOAs are quite similar to those provided by the manufacturers. Another major drawback of our study is the relatively small number of patients. The use of three different types of sutured valves in the AVR group could be considered as a possible limitation because each valve has a different design and EOAs. On the other hand, it confirms the largest Perceval areas compared to various sutured valves considered. A longer follow-up of the patients included in this study is necessary to determine clinical outcome differences among groups. Finally, this is an observational prospective study not of randomized design, therefore not recognized bias could occur.

\section{Conclusion}

Previous studies compared nominal sizes regardless of the EOAs. For the first time, we analyzed the theoret-

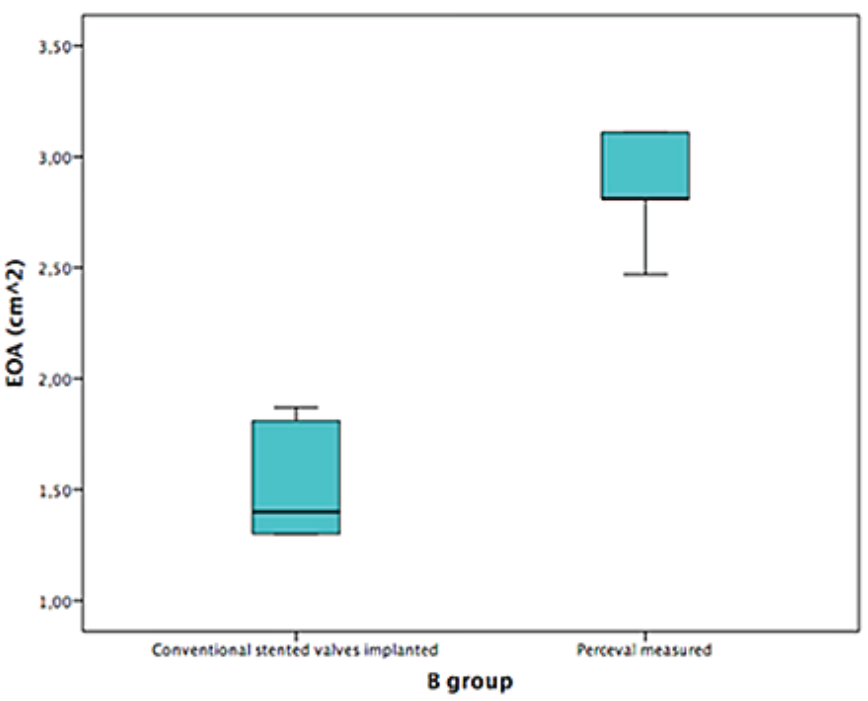

Figure 3. The boxplots show the significative statistical difference between the EOAs of the implanted and the measured valves in both groups (A-B) always in favour of the sutureless Perceval bioprosthesis. 
ical EOAs of the sutureless versus sutured bioprosthesis. For every single patient considered, the EOA was significantly larger with the sutureless rather than with the sutured bioprosthesis that could fit. In SU-AVRs, the benefits go far beyond the CPB and cross-clamp time reduction, providing larger EOAs resulting in a better hemodynamics performance and less risk of patient-

\section{References}

1. Santarpino G., Pfeiffer S., Concistré G., et al., The Perceval S aortic valve has the potential of shortening surgical time: does it also result in improved outcome? Ann Thorac Surg, 2013. 96(1): p. 77-81; discussion 81-2.

2. Shrestha M., Fischlein T., Meuris B., et al., European multicentre experience with the sutureless Perceval valve: clinical and haemodynamic outcomes up to 5 years in over 700 patientsdagger. Eur J Cardiothorac Surg, 2015.

3. Moriggia S., Trumello C., Buzzatti N., et al., Aortic sutureless Perceval valve for small root in concomitant mitral valve replacement. J Heart Valve Dis, 2015. 24(2): p. 187-9.

4. Lio A., Miceli A., Solinas M., et al., Initial Experience with Sutureless Sorin Perceval S Aortic Prosthesis for the Treatment of Prosthetic Valve Endocarditis. Thorac Cardiovasc Surg, 2015. 63(6): p. 501-3.

5. Nguyen A., Fortin W., Mazine A., et al., Sutureless aortic valve replacement in patients who have bicuspid aortic valve. J Thorac Cardiovasc Surg, 2015. 150(4): p. 851-7.

6. Gilmanov D.S., Solinas M., Kallushi E., et al., Sutureless Aortic Valve Replacement for Aortic Incompetence. J Card Surg, 2015.

7. Gonzalez-Juanatey J.R., Garcia-Acuna J.M., Vega Fernandez M., et al., Influence of the size of aortic valve prostheses on hemodynamics and change in left ventricular mass: implications for the surgical management of aortic stenosis. J Thorac Cardiovasc Surg, 1996. 112(2): p. 273-80. prosthesis mismatch. However, well-designed clinical randomized trials are necessary to confim this trend and to fully compare the hemodynamic parameters.

Acknowledgement: The authors would like to thank LivaNova for providing the in vitro effective orifice areas of Perceval.
8. Della Barbera M., Basso C., Valente M., et al., Pre-implantation collapse in the Sorin Perceval S Sutureless prosthesis does not affect pericardial graft structure Cardiovascular Pathology 2013. 22: p. 43

9. Magovern G.J. and H.W. Cromie, Sutureless Prosthetic Heart Valves. J Thorac Cardiovasc Surg, 1963. 46: p. 726-36.

10. Flameng W., Herregods M.C., Hermans H., et al., Effect of sutureless implantation of the Perceval $\mathrm{S}$ aortic valve bioprosthesis on intraoperative and early postoperative outcomes. J Thorac Cardiovasc Surg, 2011. 142(6): p. 1453-7.

11. Ranucci M., Frigiola A., Menicanti L., et al., Aortic cross-clamp time, new prostheses, and outcome in aortic valve replacement. J Heart Valve Dis, 2012. 21(6): p. 732-9.

12. Konig K.C., Wahlers T., Scherner M., et al., Sutureless Perceval aortic valve in comparison with the stented Carpentier-Edwards Perimount aortic valve. J Heart Valve Dis, 2014. 23(2): p. 253-8.

13. Christakis G.T., Buth K.J., Goldman B.S., et al., Inaccurate and Misleading Valve Sizing: A Proposed Standard for Valve Size and Nomenclature. Ann Thorac Surg, 1998. 66: p. 1198-203.

14. Fujita B., Kutting M., Scholtz S., et al., Development of an algorithm to plan and simulate a new interventional procedure. Interact Cardiovasc Thorac Surg, 2015.

Received: 04/02/2016

Accepted: 06/03/2016

Published: 15/03/2016

Disclosure and conflicts of interest:

Dr. Stefano Moriggia is proctor for Sorin Perceval. The other authors have no conflict of interest to disclose.

\section{Corresponding author:}

Dr. IIgor Belluschi

Mail: igor.belluschi@gmail.com 